\title{
Group based exercise reduced falls in community dwelling people $\geq 70$ years of age
}

\section{Day L, Fildes B, Gordon I, et al. Randomised factorial trial of falls prevention among older people living in their own homes. BMJ 2002;325:128-31. \\ QUESTION: In community dwelling people $\geq 70$ years of age, is exercise, home hazard management, or vision improvement more effective than no intervention for reducing falls?}

Design

Randomised (allocation concealed*), unblinded,* full factorial, controlled trial with 18 months of follow up.

\section{Setting}

Urban community in Melbourne, Victoria, Australia.

\section{Participants}

1090 participants $\geq 70$ years of age (mean age $76 \mathrm{y}, 60 \%$ women) who were living in their own accommodation and allowed to make modifications. Exclusion criteria included people expecting to move within 2 years; participation in regular to moderate physical activity with a balance improvement component in the previous 2 months; inability to walk 10-20 metres without rest, help, or experiencing angina; and serious comorbidity. Follow up was $89 \%$.

\section{Intervention}

Participants were allocated to group based exercise (exercise) ( $\mathrm{n}=135)$, home hazard management (home hazard) $(n=136)$, vision improvement $(n=139)$, exercise plus home hazard $(\mathrm{n}=135)$, exercise plus vision improvement $(\mathrm{n}=136)$, home hazard plus vision improvement $(\mathrm{n}=137)$, all 3 interventions (ATI) (135), or no intervention (control) $(\mathrm{n}=137)$. Participants allocated to exercise attended a weekly exercise class of 1 hour for 15 weeks, supplemented by daily home exercises, which were all designed to improve flexibility, leg strength, and balance. Home hazard involved removing or modifying home hazards. Vision improvement required eye testing with referral to the usual eye care provider if the vision tested below predetermined criteria.

\section{Main outcome measures}

Time from randomisation to first fall.

\section{Main results}

Analysis was by intention to treat. The rate of falls was lower in each of the exercise, exercise plus vision improvement, exercise plus home hazard, and ATI groups than in the control group (table). The home hazard, vision improvement, and home hazard plus vision improvement groups did not differ from the control group for rate of falls (table).

\section{Conclusion}

In community dwelling people $\geq 70$ years of age, exercise alone or in addition to home hazard management or vision improvement, or both, was more effective than no intervention for reducing falls.

*See glossary.

\section{COMMENTARY} with $\geq 4$ risk factors. programme was not assessed. interventions are not effective unless combined in a multifaceted approach. the community. N Engl J Med 1988;319:1701-7. vention.J Am Geriatr Soc 2001;49:664-72.
Sources of funding: National Health and Medical Research Council; Victorian Department of Human Services; City of Whitehorse; Victorian Health Promotion

Foundation; Rotary; and National Safety Council.

For correspondence: Dr L Day, Monash University, Clayton,

Victoria, Australia.

Lesley.Day@

general.monash.edu.au

Approximately $35-40 \%$ of community dwelling elderly people fall each year; $10-15 \%$ of falls are associated with a major injury. Predisposing factors include advanced age history of previous falls, cognitive impairment, use of psychotropic medications, impairments in gait and balance, and poor vision. Tinetti et al found that the percentage of elderly people falling increased from $8 \%$ for those with no risk factors to $78 \%$ for those

The study by Day et al describes a randomised, but not double blind, prospective trial examining both single and multiple interventions for preventing falls among well elderly people. The interventions studied were simple and relatively inexpensive, and resulted in improvements in mean strength and balance range and a decrease in the average number of home hazards. Other interventions found useful in previous studies, such as Tai Chi and hip protectors, were not examined. The outcome measure, time to first fall, did not distinguish falls with and without injury, and the cost effectiveness of the

The study provided valuable information on the duration and intensity of exercise needed to prevent falls but was limited to community dwelling, relatively healthy seniors. The applicability of its results to patients with cognitive and functional impairment remains unknown. A recent American Geriatrics Society Guideline for Prevention of Falls in Older Persons recommends multifactorial interventions for community dwelling older persons, including gait training and advice on the appropriate use of assistive devices; review and modification of medications; exercise programmes, with balance training as one of the components; and possibly modification of environmental hazards. ${ }^{2}$ The results from this study confirm the guideline recommendations and specify that exercise, especially balance exercise, is beneficial and that other

Suzanne Fields, MD

State University of New York at Stony Brook Stony Brook, New York, USA

1 Tinetti ME, Speechley M, Ginter SF. Risk factors for falls among elderly persons living in

2 Guideline for the prevention of falls in older persons. American Geriatrics Society, British Geriatrics Society, and American Academy of Orthopaedic Surgeons Panel on Falls Pre-

Group based exercise (exercise), home hazard management (home hazard), or vision improvement (visual) v no intervention (control) for reducing falls in community dwelling people $\geq 70$ years of age at 18 months $\dagger$

\begin{tabular}{|c|c|c|c|c|}
\hline Outcome & Comparison & Event rates & RRR (95\% Cl) & NNT (CI) \\
\hline \multirow[t]{7}{*}{ Patients having $\geq 1$ fall } & Exercise $v$ control & $56.3 \% \vee 63.5 \%$ & $18 \%(3$ to 30$)$ & 14 (8 to 91$)$ \\
\hline & Home hazard $v$ control & $57.4 \% \vee 63.5 \%$ & $8 \%(-8$ to 22$)$ & Not significant \\
\hline & Visual $v$ control & $60.4 \% \vee 63.5 \%$ & $11 \%(-4$ to 25$)$ & Not significant \\
\hline & Exercise plus home hazard $v$ control & $53.3 \% \vee 63.5 \%$ & $24 \%(5$ to 40$)$ & 10 (6 to 42$)$ \\
\hline & Exercise plus visual $v$ control & $48.5 \% \vee 63.5 \%$ & $27 \%$ (9 to 42$)$ & $9(6$ to 46$)$ \\
\hline & Home hazard plus visual $v$ control & $56.9 \% \vee 63.5 \%$ & $19 \%(-2$ to 35$)$ & Not significant \\
\hline & Exercise plus home hazard plus visual $v$ control & $48.1 \% \vee 63.5 \%$ & $33 \%(12$ to 49$)$ & 7 (5 to 28$)$ \\
\hline
\end{tabular}

